\title{
Reading the river through 'watercraft': environmental engagement through knowledge and practice in freshwater angling
}

Sally Eden, Department of Geography, University of Hull, Cottingham Road, Hull, HU6 7RX. s.e.eden@hull.ac.uk

and

Christopher Bear, Institute of Geography \& Earth Sciences, Aberystwyth University, Llandinam Building, Penglais Campus, Aberystwyth, SY23 3DB. c.bear@aber.ac.uk

Note: This is the pre-published version. The final version was published in 2011 in Cultural Geographies volume 18, number 3, pages 297-314, DOI 10.1177/1474474010384913.

\begin{abstract}
This paper examines how freshwater anglers in northern England 'read' rivers as landscapes and work with them relationally, through various sorts of embodied knowledge-practices, as part of their angling activity: processes that they call 'watercraft'. We use this example of environmental engagement to go beyond the visual engagement with landscapes that has been associated with modernity's disconnection from nature, to show how people develop skills of environmental interpretation, mapping and nonvisual sense-making. By focusing upon angling as a practice, we also seek to go beyond the restrictive cognitive and rational ways of knowing nature that are often the focus of 'public engagement'. Instead, we argue for a more sophisticated, intimate and multisensory notion of specifically environmental engagement through practice, to challenge these assumptions of disconnection.
\end{abstract}

\section{Introduction}

This paper is about how people encounter water environments through recreational fishing. In terms of regular participation, Sport England ${ }^{1}$ estimate that fishing (inland and sea) is the $18^{\text {th }}$ most popular sport in England, with 0.7\% (c.281,083) of adults fishing at least once a month. Many more people participate more occasionally: an estimated 3.5\% of adults fish at least once a year, with 1.357 million rod licences sold in England and Wales in 2008-9. ${ }^{2}$ This large group of people and their regular encounters with the water environment has been little studied and might seem an esoteric choice for academic research, but it is distinctive and significant in several ways.

First, we focus on how people engage specifically with water as an environment. Water is a different world: unlike land and air, water is not an everyday medium in which humans live and breathe, but is special for us (as terrestrial animals) and thus requires different qualities and perceptions than other sorts of environmental engagement and recreation. Water moves rapidly, is often unpredictable and renders things (animals, plants, rocks, sediment) within and beneath it largely invisible to humans above it. Freshwater anglers thus read rivers and lakes as landscapes through various sorts of knowledge-practices as part of their angling activity: specialised processes that they call 'watercraft'. We therefore contrast the particular case of water recreation with recreation in other environments, especially on land through walking, which has been studied more frequently, ${ }^{3}$ to emphasise the heterogeneity of environmental engagement across space and time and how environmental engagement is shaped not merely by the qualities of humans in that engagement, but also by the qualities of environments.

Second, these qualities are also shaped in the encounter of angling. Anglers do not merely react, but become different sorts of humans from others, including different from ourselves as non-angling researchers. Encountering the special environment of water requires and 
develops what we might call 'water subjects'4 through ongoing, long term interactional knowledge-practices. That is not to say that all anglers become equally (or even highly) proficient in 'watercraft' - although the angling community shares enjoyment and 'tips' about how best to catch fish, anglers also very widely diverge in their opinions about fish, water and all related aspects of angling practices and policies. To put this another way, water is a different world and thus harder to know, yet anglers (more than other humans, but still not completely) attempt to be part of it.

Third, as well as this direct and mutual human-water encounter through angling practices shaping humans, angling also shapes water environments in very material ways. Anglers use their watercraft to design and implement environmental management themselves, especially through collective actions by clubs on the waters that they lease. There is little room in this paper to do more than briefly outline these various actions ${ }^{5}$, but they include stocking rivers and lakes with tens of thousands of juvenile fish (sometimes of nonnative species) every year, reshaping river channels and banks with bulldozers, dredging out sediment and vegetation from river channels and planting vegetation around water bodies. Also, anglers influence the environmental management practised by others, especially the Environment Agency of England and Wales which has a statutory duty to protect the fisheries that angling depends upon, because they lobby and participate in policy debates, formally and informally. Watercraft thus becomes not merely a way to know water, but often a way to improve it with significant ecological, hydrological and political consequences that depend upon underlying, often barely acknowledged beliefs.

To consider watercraft as a particular set of environmental knowledge-practices, this paper first briefly outlines work in human geography, sociology and anthropology about how humans engage with environments. We then introduce our empirical study and show how anglers develop skills of environmental interpretation, mapping and nonvisual sense-making in ways that are particular to the water encounter. We conclude by arguing for a mutual and multisensory notion of environmental engagement that considers not merely human perception but also how environments, such as water, also shape that encounter.

\section{Environmental engagement}

Researchers, policy makers, thinktanks and popular writers of all stripes commonly argue that human society today (usually meaning in the developed world) is increasingly disconnected from nature, through urbanisation, indoor living, technology and pollution. ${ }^{6}$ These arguments are not new. Indeed, parts of today's environmental movement originated in a backlash against the negative effects of urbanisation and industrialisation in the late $19^{\text {th }}$ century, as part of the Romantic sensibility. In the $20^{\text {th }}$ century, these ideas were perpetuated through codes of conduct developed to teach or force urbanised visitors to behave 'properly' in the countryside - something that they were increasingly failing to do because of their urbanisation. ${ }^{7}$ But such arguments assume a division between nature and human society that has been rejected by many researchers, who have emphasised instead the heterogeneity and relationality of how humans connect with and mutually coproduce nonhumans, including animals, plants and landscapes. ${ }^{8}$

But this does not mean that environmental engagement can be seen as unproblematic; rather, seeing environmental engagement in such relational terms makes it more complex and contingent. Macnaghten" shows that people find little resonance between ideas of 'the environment', especially on a global scale, and their own lives. Rather, "there are many different 'environments', each connected to people's particular concerns, priorities, social relationships and responsibilities." These heterogeneous ways of associating mean that "there 
is no nature as such, only natures." ${ }^{10}$ But how do we trace the associations ${ }^{11}$ of environmental engagement between diverse humans and nonhumans, in different places and times? What transformations do these have upon each other? Surprisingly, the last few years have seen little research in human geography into how humans perceive the environment in such terms, despite the potential of such theoretical frameworks. The work that has been done tends to consider shallower, more sporadic engagements with environments, as exemplified through tourism and other forms of consumption. ${ }^{12}$ In comparison, angling, particularly by regular participants, is often a more intensive and reciprocal engagement, more closely tied to identity and personality. Yet angling and other outdoor sports like hunting are often distinguished from other environmental recreations precisely as 'consumptive' rather than 'appreciative' recreations, ${ }^{13}$ with correspondingly negative associations.

In this paper, we take environmental engagement to be an ongoing process of association, of translation, of relationality and mutual coproduction. ${ }^{14}$ As the angler changes in terms of skills, technology and perceptions, so too do the fish, the river water and the riverbank: environmental engagement is thus interactive, in that it both makes places as water environments and makes people as water subjects, echoing Waitt et al.'s theorisation of walking as a 'place-making' practice. ${ }^{15}$

In this paper, we also explicitly link knowledge with practice, because engagement is necessarily about both doing and knowing, and not merely in a cognitive sense, as we show. We specifically look at interactions around skill, using "an ecological approach that situates the practitioner, right from the start, in the context of an active engagement with his or her surroundings." I6 Ingold conceptualised skill as "both practical knowledge and knowledgeable practice", informally acquired as it is through bodily engagement as "a property... of the total field of relations." 17 Such an interpretation reflects the turn from discourse to practice in the $2000 \mathrm{~s},{ }^{18}$ reemphasising embodied practice and encounter to address the earlier emphasis upon representation and the visual consumption of the environment in modernity. ${ }^{19}$

We draw on empirical work with people regularly fishing on one or more of three rivers in northern England: the Swale, the Ure and the Esk. The Esk is a small river that runs through part of the North York Moors National Park; the Swale and the Ure are part of the large Ouse catchment that runs down into the Humber estuary. However, most anglers we spoke to fished many different rivers and lakes over the course of a season (including overseas on holidays), so although this focus on three rivers spatially restricted our sampling process, it did not restrict the experiences of our anglers. Hence, we refer here to comments made also about other rivers in the area, including the Wharfe, the Calder, the Trent, the Tees and the Ouse.

To form our sample, we initially approached clubs which owned or leased fishing rights on the three rivers. We ran two focus groups: one of anglers who regularly fished on the lower Swale and its nearby stillwaters for coarse fish like chub, barbel, roach, dace and pike, and one of anglers who regularly fished the middle Esk for game fish like salmon and trout. We subsequently interviewed some of these anglers in more detail and recruited other anglers by attending matches and other club events, by snowballing recommendations, by talking to owners/managers of tackle shops and by posting on an online fishing forum.

In total, we conducted 60 semi-structured interviews with anglers in 2006-8, some in their own homes, pubs or bars but many on the riverbank, especially during day-long matches on the Swale and Ure during the 2007-8 coarse fishing season. Our sample was specifically of 
regular anglers, although of varied frequency- some would fish three or four times a week, but others only fortnightly or monthly at a club match. ${ }^{20}$ Except where prevented by poor weather conditions, interviews were digitally recorded, fully transcribed and analysed through thematic coding to saturation using NVIVO 7 qualitative analysis software. Participants have been given pseudonyms.

Profiles of the angling population in the UK vary. The EA suggested that over a fifth of anglers are women, ${ }^{21}$ but we found much lower proportions and several clubs that we contacted with 70-170 members had either no women members or only a handful. Indeed, as our study progressed, we became concerned about speaking to so few women and attempted to target more for interview. In this, we were unsuccessful - indeed, the refusal rate for women anglers was about 4 out of 6 approached (depending what one counts as a 'refusal'), compared to about 4 out of 64 men approached. The resulting male bias in our study does however seem to reflect that in the sport generally. Other than a male bias, angling shows little skew by age or socioeconomic status. ${ }^{22}$ However, most of our participants were of working class origins and our sample was skewed towards the older anglers, although the full age range was $17-83$.

\section{Reading the river}

We begin by looking at how anglers make sense of the river as an angling space. When we talked to anglers about 'reading the river', this phrase seemed to resonate with them as accurately describing their embodied practices on the riverbank. The other term they used (12 anglers, unprompted) to describe these knowledge-practices was 'watercraft'. When asked to define 'watercraft' in a focus group by the facilitator, Nick says it is "being able to read the water and try and understand what's happening below," thus engaging precisely with (and also distinguishing by name) the particular qualities of water as an environment. Both 'reading the river' and 'watercraft' evoke environmental engagement through watching the river environment and interpreting riverbank characteristics and water surface behaviour as proxies for fish presence:

Watercraft. You've looked at the river so many times, you comprehend where the flow is going, where it slows down. (Charles)

I can recognise now where a fish is likely to be lying by the movement of the water. (Cliff)

Reading the water surface through watercraft becomes something that anglers learn how to do in their interaction with different waters over time, involving their bodies, senses and minds. Discussing whitewater kayaking, Sanford considers how the river is a 'fluid text' requiring whitewater kayakers to "develop their river reading skills." 23 But is is more than a visual reading: their skill is developed ecologically, in the context of their bodily activity and their environmental relations. ${ }^{24}$ Some anglers therefore found it difficult to articulate in words a practice that can only be properly felt, but others, especially those who also wrote articles (another form of articulation) for fishing magazines, attempted to explain these embodied practices more explicitly:

Just a combination really of experience and what anglers call watercraft. You can sort of just look at a river and look at what the flow's doing and the current's doing, and once you have got an idea of the nature of the river bed... basically you walk the length and you look at places where the flow is kicking away because of whatever deflections from the river bank or submerged willows, to give you some protection from the debris that is coming down in the flood water. (Malcolm) 
Others used examples to show how watercraft involves knowledge-practices to identify and interpret the features and behaviour of the water surface, not in terms of its abstract appearance (see Figure 1), but in terms of the practices of fish, the places where they would hide or congregate and the fleeting signs of their presence in disturbing the water's surface, thus reading the water as an environment of/for life and liveliness:

Some people can look at a river and see a break in the river or a roll in the water and say 'oh, there's a big snag there' or 'that's a deep pool.' It comes with experience. (Keith)

in low water levels I've seen fish as I'm walking up the river back to the car in an evening and by the waves fish have obviously been laying there and I've frightened them. (Sandy)

But seeing fish (especially game fish) is difficult, because fish underwater are often "hidden" (Max) and thus invisible from the angler's position on the bank, due to the angle (Bert therefore described climbing trees to get a better view of fish in clear water) and due to the human position 'outside' the water environment in a different sensory space. And rivers like the lower Swale and Ure also carry suspended sediment that can 'colour' the water and further obscure a view of the bed, so anglers seek other ways to see fish by proxy - by signs on the water surface, by identifying river bed shapes that are likely to have fish in residence, by rendering absence as presence:

the vast percentage of places we fish, you can't see them. It's a disadvantage, but you've got to use your watercraft and just look at areas that you think fish will hold. (Tim)

you get an idea over the years what the different signs are. But you don't just go and spot one in the water. They're that shy. Or you might see a big swirl of sand as you're walking and you'd think 'oh, there's been a fish there and it's come in and darted off' you see. (Colin)

Hence, anglers' environmental engagement is specialised and built up from long hours of practice in situ. Like many specialised forms of knowing, watercraft then develops a shared vocabulary (or jargon, to the outsider) to describe how rivers and fish behave. A simple example is 'the crease', "a bit of turbulence" between "two different paces of flow" (Damian), a visible boundary or fold on the water surface between one sort of flow and another that is recognised, described and acted upon by anglers:

there's a crease in the water, where the slow water and the fast water meets. And the chub or a lot of fish will hold in the slower water, see something coming down in the fast water, move out, take it, move back again. So they're living in the slack water, which they have to use less energy to expend to hold in that position... or they might be holding behind an obstruction in the river, where it causes the water to part and flow in different directions, and they've got that area where the flow is reduced, so they can hold and then move into the faster water and back again.

Interviewer: Can you see the crease?

Yeah, you can see where the difference of the rate of flow goes. You just watch anything that's on the top of the water - might be a bubble, might be a leaf or a bit of weed, or whatever else, a twig, and you can just watch them and see how one bit's going faster than the other. (Charles)

you also look for things like crease swims. The river might bend a bit, there's a recess in the bank, and what you might see is the flow of the river deflects away from the margins and you've got a really steady area of water. And the crease swim is the 
steady bit of water inside the main flow. And they always produce chub. Most people walk past them and don't see them. They're looking for features such as willow trees or big snags in the river, sunken trees. But some of the best swims are the ones that you don't really look at twice. But you get an eye for the river. (Tim)

Other terms abound that express these specialised knowledge-practices. Short stretches of water are commonly called 'swims', evoking the behaviour of the fish that may (but may not) live in them and evoking the water environment as a space shaped by/for nonhuman living. Other terms are: 'streamy water' meaning rapidly flowing but not turbulent (Tim); 'boiling water' for turbulent flow and eddies; 'glides' for long straight stretches of smoothly flowing water; and 'the throat of a pool' for the step down into a glide where the river bed drops in altitude and the water becomes more broken, 'ripply' (Donny) or disturbed. However, other terms used by anglers include some that geomorphologists share or the general public would recognise, like 'pools' and 'riffles' (Bert), 'eddies', 'slacks' (Mike), 'shallows' and 'rapids' (Patrick and Max).

Hence, this specialised 'environmental public' developed and shared skills of environmental interpretation and sense-making in an intimate relationality through these watery environments. And this relationality that is not only spatial but also temporal: it encompasses rhythmicity over periods of hours, days, seasons, years and decades and is not produced by underlying causal factors, but by spirals of transformation through multiple repetitions. ${ }^{25}$ Moreover, these are not merely cognitive knowledges or packages of detached 'environmental information', but part and parcel of practices and coproduced with practices. ${ }^{26}$ First, the ways in which anglers fished changed in relation to how they developed their knowledge, both in terms of their personal learning and environmental changes over a period of years and in terms of their reflexive response to changing weather and water conditions over a period of minutes during a single fishing event. Second, the knowledges were also produced through various bodily practices, such moving about to be able to see the crease better or feeling air temperature. The practice of angling thus changes contextually as the product not only of the angler but also of the river and the fish.

But these knowledge-practices are also linked with tools and other technological practices, not merely human senses and environmental conditions. Like walking boots for walkers, angling also works with "mundane technologies" which can "reshape the affordances of nature by expanding the range of possible actions available to the body" (Michael 2000, page 112). The technology of fishing gear is huge and varied, with rods and lines in particular highly diversified to suit specific target species and fish weights, as the advertising in any fishing magazine today will illustrate. More interesting from an environmental perspective are technologies that expand the angler's environmental senses, that enable them to see in/through the water environment. Anglers often chose to read the river using polarised glasses (referred to by the brand name as Polaroids) to see underneath the water surface by eliminating reflection, especially on a still but sunshiny day. They adapted and enhanced their visual senses and range, because "Polaroids allow you to see into broken or riffled water... helping you to spot your prey" (Coarse Fisherman 2008):

I'd go for a walk down the river with my Polaroids on and have a look - get a rough idea in my mind of where the deep troughs are. Some of them you can't miss them because you'll get a bank of gravel - 2-3ft deep - then it'll drop off into a trough and the river'll come back up again. (Geoff) 
But, as we suggested above, angling is a more-than-visual environmental engagement; polarised glasses and the enhanced visual sense that they provide are still insufficient to be an angler:

On a shallower river you can get an idea of it with Polaroids, but you may still feel the need to plumb the depth anyway. (Malcolm)

It has been argued that the dominant (human) sense in modernity is the visual, especially in terms of how we learn to see and appreciate the environment. ${ }^{27}$ Even arguments for appreciating 'restorative environments' often emphasise the psychophysiological benefits of seeing a 'natural' view, ${ }^{28}$ rather than being and doing something in that view. But visual dominance is problematic and needs to be challenged in favour of "multisensory" perception, ${ }^{29}$ where the whole body is immersed in the natural environment.

But senses beyond the visual might be poorly developed in some people, giving them insufficient perceptual skills to appreciate and acknowledge this immersion. For example, Waitt and Cook found that first-time kayakers tended to "deny the fluid nature of their bodies," being reluctant to touch the rocks and water around them. ${ }^{30}$ When subsequently recounting their environmental experiences, these inexperienced and perhaps less confident kayakers fell back instead on the discourses of their guides and guidebooks, which tended to emphasise the visual consumption of the environment. ${ }^{31}$

Angling demonstrates the opposite, where primacy of visual sense is challenged and becomes part of perception, rather than dominant: "we perceive not with the eyes, the ears or the surface of the skin, but with the whole body." ${ }^{, 32}$ This is well shown in plumbing the river, which is a common, even an "automatic" thing (Jacob) many anglers do when they first arrive at a fishing spot. A very simple technology - a bought or self-made lead weight on a line cast out with the rod - is used to measure the river's depth and shape:

In a river there's a deep channel, but it's a matter of finding it really. And by using a heavy weight, a weight on the end of my line, I can see by how long it takes to hit the bottom or where it comes to end up, when I pull it back in, I see how long it takes for that lead to come to the surface, so I've got an idea of how deep it is (Rex)

Unlike hikers on land, human anglers are engaging with water, a medium in which they do not live, unlike the fish that they are hunting. So other modes of perception must be applied, or their own senses enhanced, to compete with the perceptual abilities of fish in their 'home' medium of water. On familiar waters, anglers use this continued measuring to build a detailed profile in their minds of the river beneath the visible surface: "you can map out the depths in the whole area where you are fishing" (Malcolm).

It's like you looking at a road map... I can go certain lengths of the River Ure, I can go into a spot and turn round to you and say it's 12 foot deep over there and then it shelves up and it's 3 foot here and 10 foot there. (Geoff)

But even in familiar places, plumbing is a check on the changeability, the unpredictability of water environments and, consequently, of fish behaviour. For example, one of us visited a local lake with Dick, who has been fishing for several decades and was so familiar with the lake's layout that he had decided which numbered 'peg' to fish from before we even arrived. But he still checked the depth of the lake using a lead weight, letting it sink and then adjusting the float on the line above the lead so that the float sat on the water surface when the lead touched the lake bed. This was all done largely by eye (watching the float), by touch (as the 
lead hit the unseen lake bed) and by physical movement of the pole and float in continual readjustment. And all in a spot which he said he has fished many times.

Mapping and measuring the river environment in this way and building "a mental picture" (Nick and Sam) of the river bed's shape are all part of watercraft, but those pictures are embodied through practices particular to each angler's relationship with environmental conditions. As with measuring temperature, plumbing the depths is also often quantified: "you can work it out" by counting seconds as the lead falls through the water and assuming that one second of the lead falling through the water equates to roughly one foot down (Arnold), especially where the depth is too great to be judged visually, say "15-17 feet deep" (Charles). Such mental models can be tested for validity through practices of fishing (and reflexively revised) because their success can be measured by the resulting catch, although again this varies by angler and environmental conditions. Hence, the environmental knowledge practices are also reciprocal and responsive to the human-water connection:

You look at the outside and you see the flow and then you look again at a certain area where you think there might be fish and then you work it down into the swim that you're actually going to fish and you look at it three-dimensionally and every aspect possible. (Steve)

Walking, Ingold notes, "is a highly intelligent activity. This intelligence is not located exclusively in the head but is distributed throughout the entire field of relations comprised by the presence of the human being in the inhabited world." 33 For angling, environmental intelligence (as knowledge, rather than smartness) does not merely relate to measuring the size of the river bed, but also to assessing its composition and substrate, using their hands to sense what the weight is touching:

you can tell the way [the lead weight] hits the bottom. Especially with the braid because you get the feedback straight through. You can tell what the bottom's like. Whether it might be a bit weedy, muddy, gravel, whatever. And you can feel for holes and you can feel it drop down, things like this. (Andy)

when [the lead] hits the bottom and you start to pull it back you can feel what it is pulling against. And if it is gravel it will rattle, if it is going through weed it will be sort of a dull bouncing sensation, if it is silt you can feel it because you have to pull it free it will settle, so you will have to pull it free gain. So you can actually feel what the bottom make up of the river is. (Ray)

Methodologically, this raises the problem of converting into words for this journal a process which many anglers found difficult to describe, even across hours of discussion or while performing the very actions that they were describing. And they also share and learn from each other, as this exchange between angling friends illustrates:

Keith: Cast in with a fairly heavy feed on and then slowly bring it back and then you'll feel every drop and every ridge in the riverbed. As you drag it back. You can drag it back slowly and you'll feel it drop into a deeper hole or into a boat channel or whether it's coming up over a ledge.

Interviewer: You feel it through the rod by actually holding onto it?

Scott: $\quad$ Yeah. And you get an idea as well from the amount of time from it sploshing on the surface to how long it takes to hit the bottom.

Interviewer: Actually moving through the water.

Scott: $\quad$ Yeah. it gives you a rough idea of what's deep and what's shallower. Like you cast in, splash, and three seconds it's hit the bottom of the riverbed. And in 
another spot it might take a little bit longer. So you think it's took longer to get to the bottom so it's deeper there.

Interviewer: And does the bottom feel different as you pull it over?

Keith: $\quad$ A lot of that river's like a clay bottom, isn't it?

Scott: $\quad$ Yeah, some parts of it are a bit rocky.

Christine: And you can tell gravel, because it used to be dredged, didn't it? And there are some gravel areas on it and some sandy areas. A lot of it is different.

Scott: $\quad$ It's all time and practice. You can tell where it, if you're feeling for it sometimes you don't, because you know the river - but if you're trying to figure out what the bottom's like, it's just a feeling coming through the line all the way into the rod... In one area it will just be a general - you'll say soft, it's soft is the bottom - and another part of the river it'll go down and it'll feel harder... That's stony, is that. It's just practice and time. You just learn what things feel like.

Using the lead and making sense of what it tells the angler is a complex environmental knowledge-practice that brings to the fore the embodied skill and technique that "comes with experience" (Keith). Ingold ${ }^{34}$ thus discusses how technique is much more than merely operations, but skills as both practical knowledge (that can be put into practice to catch a fish) and knowledgeable practice (that draws on knowledge to enable practice). And in this process the angler is also changed, linked in their relationship with the river and its water:

I look for very specific types of water at the moment. So I have got to have that mapped out in my head and if I don't then I am probably not in the right place. I have got to know exactly what that bit of river is like for it to work. (Ray)

These are again connections between knowing and doing that only together can produce angling as knowledge-practice. In this way, fishing is not necessarily a science, nor even an art, but a craft: "it's touch and feel on the day" (Ernie) because "you can't fish properly with a pair of mittens on" (Tim), as they impede your sense of touch. Particularly when night fishing, the visual sense, while not lost, is reduced and other senses become important for the enhanced water subject:

it doesn't go real dark to your eyes... if you're out all the time and could still see to put your bait on, you could feel your bite, you could feel it. (Neil)

\section{Different readings}

An essential point to make here is how these knowledge practices differ. For example, six anglers interviewed normally used a thermometer to take the temperature of the water, especially in winter when low but changing temperatures would most influence fish behaviour. Some (mainly self-described specialists and obsessives) considered thermometers "critical" because even one or two degrees of difference matter to fish and angler behaviour (Tim). But most anglers interviewed were less enthusiastic about the ability of technology to improve their environmental understanding and success (by way of catching). Hence, technology was not an automatic choice for all anglers: several said they used a thermometer in the past but had stopped or rarely did so anymore (Alistair, Jack, Damian, Ray, Patrick), because it makes them feel pessimistic:

it's a definite interference with the head if you find out it's too low. So you might as well fish with confidence [without a thermometer] and you never know what you can achieve until you try. (Damian, also Patrick)

Hence, specific technologies do not determine human-environment relations: their effects are ambiguous, ${ }^{35}$ because they are always contingent on the particular relation of their use (or 
nonuse), part of how knowledge-practices are differentiated in space and time. To simplify: there is no one way to fish, no 'pure' connection, no singular water subject; instead we find multiplicity and multivalency in human-environment relations. ${ }^{36}$ Moreover, for some anglers, even simple technology seemed to shift fishing from a moment of pleasure to something "too scientific" (Ted), taken to "much further extremes" (Ian) than is necessary, and lacking in "fun" (Sarah). Using (and trusting) a thermometer thus becomes part of differentiating between skill levels and between purposes of environmental engagement through practice: Dick said that "top men" who win competitions use thermometers, not pleasure anglers like himself. Instead, many anglers preferred their own senses, refusing to use a thermometer "because I can tell you when it's cold and when it's not" (Harry), so their own senses are sufficient engagement with the environment and further technology would be unwelcome interference.

Similarly, although plumbing the depth is common practice, some anglers saw it as unnecessarily specialised engagement - more like work than fun:

somebody who's really, really keen will possibly set on and plumb the depths and play about for half-a-day, will a really serious angler. Plumb the depths and find out where all the shallows are and everything else, and basically try to get a mental picture in their heads of what under the water is like. I'm not that good. And I'm not that keen. I do it purely for pleasure. (Frank)

a lot of people are angling out to be more scientific - I know I use the monitors and I gauge the river levels, but there's people who do try to blind you with science. I do think it's unnecessary. I think it's a very simple, straightforward sport. If you've got an eye for the river and you can read the river a little bit, as regards where you should be fishing... it's very straightforward. (Tim)

So fishing technologies are part of a relational landscape of practice, where practice combines the use of tools and the body as "a property... of the total field of relations". ${ }^{37}$ The degree and sophistication of the technology, not merely its presence or absence, are part of that relation, that association of angler, rod, bait, river, fish, weather and other devices or features. In this sense, angling is not modern or premodern ${ }^{38}$ but relational and heterogeneous in how it is coproduced through technological and nontechnological connections between the worlds of the angler, their gear, the river and the fish.

Drawing on theology, Snyder sees casting in fly fishing as 'ritual practice' and the rod as a 'ritual tool' for extending the angler's ability to penetrate the mysteries of the river and a companion in the angler's environmental engagement with the sacred. ${ }^{39}$ To put this slightly differently using literature from science and technology studies (STS), we can see the rod as a technological actor that, together with the human body and the river water, produces 'the angler' as a blended human-technology-water assemblage. Similarly, Dant talks of the 'windsurfer' as entity with board and body and Sanford talks of whitewater kayakers who "essentially wear their boats." 40

Hence, reading the river is not simply reading a text, but reading a situation, through the body and all its senses, not merely the visual. Anglers' environmental knowledge-practices are thus also strongly performative. Sanford suggest that, for kayaking, "paddling is an orthopraxy [rather than an orthodoxy], in which correct performance of these ideas embodies or manifests the religious experience." ${ }^{41}$ In other words, the sacredness of nature is not given but generated through this embodied, experienced relationship. Our anglers were less given 
to such flights of spiritual interpretation, but they did focus upon practice - both in the sense of doing things, but also in the sense of repeated doing, experimenting, evaluating, adjusting and doing again to reflexively learn for themselves.

But even such simple connections are complex. Some anglers would prefer more intimate and embodied engagement with the water than sophisticated technology implies. For example, Nick talks about how, when flood waters suddenly run through the stretch of river where he is fishing, he can feel the colder water wash around the outside of his waders, cooling his ankles. Instead of a lead weight, Sid describes wading through the River Nidd "one summer's day in my swimming trunks" (because the water was too deep for his waders) to remove weed from the swims and, as a result of walking the river bed, "I knew where there were deep bits and shallow bits and gravel bars and mud bars!" And when Donny is explaining to one of us what kind of flies he decided to use as bait one day on Cod Beck, a tributary of the Swale, he pulls stones up from the shallow river bed and turns them over in his hands to see what kind of nymphs or other larvae are crawling there (see Figure 2), because this will vary by environmental conditions and seasons. Touching the water, the rocks and the animals are part of angling as a knowledge-practice:

"Nothing gives you such intimacy with the stream (barring tumbling in) as standing up against it. Also, there is no way of learning the bottom of a river so good as that of walking about on it."42

We need to be clear at this point: we do not mean to argue that anglers' environmental engagement is unmediated (or premodern), if they reject some "fancy gear" and "gadgetry" (Ted), only that the technology that they choose to associate with is perceived as more or less human in extending their own bodies, especially their fishing rod, to deal with the challenge of engaging with the largely invisible water environment. Other technologies, including sonar-based fish detectors, were rarely used by anglers we met (with the exception of Scott), although many were highly proficient with information technology, using digital cameras, keeping fishing diaries online and using Google maps to 'look for twists' in a river to explore later (Bert). ${ }^{43}$

And 'seeing' the environment in this way is a product of long practice, experience and specialisation. Hence, as non-anglers with our more 'everyday' nonspecialised ways of environmental engagement, we were rarely able to 'see' the rivers we visited during this study in these ways, even when anglers tried to point out such features to us. Moreover, different anglers did not necessarily use the same skills or to the same degree: even anglers in the same small club, fishing on similar stretches of river, vary considerably in their knowledgepractices, with some far more analytical and contemplative than others. Angling is not, therefore, a uniform experience and some of the more experienced and/or obsessive anglers talked about how other people, especially people they are introducing to fishing, did (or could) not see the things that they do, at least not until they had invested the time and effort into practising in situ:

if I go down onto the real low stretches of the Ure where it's wide, deep and all those bankside willows and that, there's not that much nature to the flow. There is current variation but it's subtle. You've got to really look for it. You can struggle. (Tim)

[when teaching someone to fish] I would be more inclined to take someone out and spend eight hours walking a river and not actually fish at all, because in the eight hours they will learn more than they could do in 200 hours of fishing, because that is the key to fishing at the end of the day, if you can read a river, then you are almost there. (Ray) 


\section{Reading the river as learning about space}

As well as an embodied and technologically relational practice, angling is a spatial practice, especially through learning in particular places. Crouch discusses how individuals make sense of the world through such embodied processes and thus build 'lay geographical knowledge. ${ }^{, 44}$ Anglers learn to fish by 'experience,' 'experimentation' and 'trial and error'. Angling is thus 'the sport of experience' (Alistair, the youngest angler we interviewed) and 'you learn from not catching... you analyse what you have done and try and work out why you've not caught' (Ray). Hence, 'a lot of a fisherman's experience will come from his own gradual reading of the river and he will learn all sorts of things' (Donny, his emphasis).

there are certain places where there are no rocks visible and you know there are no rocks underneath and you know that the fish will be around those rocks that are underneath the surface, though you can't actually see them. It's just because you fish regularly enough and usually when you've been fishing for sea trout or salmon you've got your damn spinner caught on that rock - you know it's there. (Ian)

But learning is embodied and cannot be easily taught or explained verbally or even demonstrated: "there's just certain skills but you just pick it up by practising and watching others" (Bill). Experimentation involves "a lot of things I've never been shown" (Neil) because "You can't learn how to cast out of a book" (Thomas). Hence, such technique is not merely something that can be taught, but is inherent, instinctive, intuitive (Ray) or simply something that people are born with (or not) - "something you can't teach people" (Ernie), that you gain almost by "osmosis... you may have caught a fish in that particular spot three, five, six, ten times previously. Therefore, in your mind you think - or possibly even subconsciously - "that's a good spot"' (Ian). Knowledge comes through and into practice as anglers are made in the encounter of angling; knowledge in many ways is practice in that "we can only know nature as bodies-in-the-world; as bodies doing nature, from somewhere, in a particular way". 45

In contrast to sports such as climbing or mountaineering that seek to 'conquer' nature, Sanford therefore argues that river sports are "more humble" in embodied learning through "instant feedback" from the water environment as the kayaker moves through it, although Cloke and Perkins note the opposite for whitewater rafting in New Zealand which is promoted as 'conquering nature'. ${ }^{46}$ However, for many of our anglers, learning for yourself through your own body and environmental experiences becomes part of what they enjoy, comparing unfavourably to the disembodied and immediate learning proffered by modern technology:

if you wanted to find out about [a club's] water, you'd go on the website, click onto the menus, look at it and make up your mind. It's all done for you. Again, I don't like that. We used to find it out ourselves. Specimen hunters, when I started, there were relatively few of us, so it was a learning process. And that's why I enjoyed it. (Tim)

The unpredictability of river environments also becomes a positive quality for enjoyment, learning and even excitement. "One can never really run a river with rote knowledge," as Sanford writes of whitewater kayaking, ${ }^{47}$ because of changeability across time (e.g. between seasons) and space (e.g. between rivers). Hence, transferability from place to place is limited, yet this very unpredictability of a new river or season often gives anglers pleasure:

you never stop learning. Because rivers do change, they're not a static environment.

They're changing all the time. So you do learn an awful lot (Craig) 
That's what I like about fishing. It's not catching fish - it's not the amount you catch, it's how you do it and what you get out of it on the day. Education. We all want to learn, don't we? We all want to understand and comprehend. (Charles)

\section{Conclusions}

In this paper, we have shown that anglers are shaped through their encounters with water environments, becoming different humans from other non-anglers and from the anglers they were before, not least through abilities/qualities to perceive water environments more (but not completely, not as fish $\mathrm{do}^{48}$ ). The water environments that they encounter enable these special abilities - indeed, make them necessary if anglers are to fish successfully, because of the particular qualities of water that challenge human perception. ${ }^{49}$

We began this paper by noting that angling is a minority sport, but an even smaller minority of anglers regularly participate to the degree shown in our empirical work. So, few people have these abilities in relation to water, certainly compared to how many people have abilities in relation to more common environmental engagements, such as walking. And because few people engage with river waters beyond the visual, which means that anglers are more likely to be called upon or become involved in managing such waters, both collectively and voluntarily within angling clubs through (local) hands-on practice and also individually and more formally through representing stakeholders or 'the public interest' in agencies and committees that shape wider environmental policy about rivers and the water environment, e.g. as part of the Environment Agency in England and Wales. Anglers thus became representatives of environmental interests in policy circles because of their specialised knowledge, their perceived watercraft and their accompanying enthusiasm for water policy. However, anglers may also create conflict with other sorts of users once there: for example, the watercraft of canoeists and swimmers (although little analysed) is likely to differ from that of anglers, so conflicts over access and disturbance between these different groups are often politically highly charged.

We would also emphasise that, even as anglers are shaped by their interaction with rivers, they are shaped heterogeneously and sometimes in conflicting ways. Even within this relatively small minority of the British public who regularly go fishing, anglers and angling practices vary greatly depending on conditions, technologies, lifestage, experience and even whim. Macnaghten and Urry suggest that there is not one nature or countryside, but multiple natures and multiple countrysides because of people's "diverse spatial practices." ${ }^{50}$ Hence, there are multiple rivers, each engaged through diverse knowledge-practices in individual encounters in space-time and each shaped materially through the actions prompted by those knowledge-practices.

This means that 'the angling community' referred to in policy is far from monolithic, because different anglers develop and support contradicting viewpoints (learning from/through their diverse environmental engagement) as to how best to protect and nurture water environments and their fish stocks into the future. All our interviewees belonged to angling clubs and many helped to run them as (in some ways) environmental management committees that dredged river channels, stocked rivers and lakes with fish and stabilised eroding river banks in areas that they owned or leased. How they (choose to) do this relates directly to the environmental knowledge-practices examined in this paper, so water environments are directly shaped and influenced because of their convictions about what rivers and lakes should be like. Angling thus compares with other spatial practices like walking and (sea) swimming that "make and 
remake different kinds of countryside spaces", 51 not least by often implementing their watercraft far more directly through hands-on environmental management.

This diversity of watercraft, of interpretations of what is good and what is needed, is gained through multiple heterogeneous interactions and so may result in a patchwork of management regimes. Individual angling clubs may choose different approaches even within 500 metres of each other along a river, depending on the views of their members, and their knowledgepractices will shape rivers in different ways (more/less fish, more/less vegetation, deeper/shallower river curves) depending on their knowledge-practices.

Finally, angling, surfing, outdoor swimming, canoeing may each be a 'minority sport' in terms of absolute numbers, but their 'minorities' are often highly enthusiastic about water politics. Some have argued that environmental experiences like angling encourage an environmental ethic amongst participants, as part of a duty of care to 'give back' to an environment which has given them so much pleasure. ${ }^{52}$ In this way, environmental engagement is not merely about the personal encounter and environmental relationality we have focused upon in this paper, but also about the wider political engagement which that may also promote or sustain. However, little research attention has so far been paid to this question of collective environmental ethics amongst what we might call 'communities of recreational practice'. Further research would therefore be especially valuable in exploring the broader, more traditionally political consequences of environmental engagement beyond what has been possible in this paper.

\section{Acknowledgments}

This paper draws from the research project 'Angling in the Rural Environment' (2006-9), which was part of the Rural Economy and Landuse Programme (Relu), funded primarily by the Economic and Social Research Council and the Natural Environment Research Council in the UK. We would like to thank all the anglers who gave us so much of their time.

\section{Figure 1. Water surface on the river Swale on 20 March 2008.}

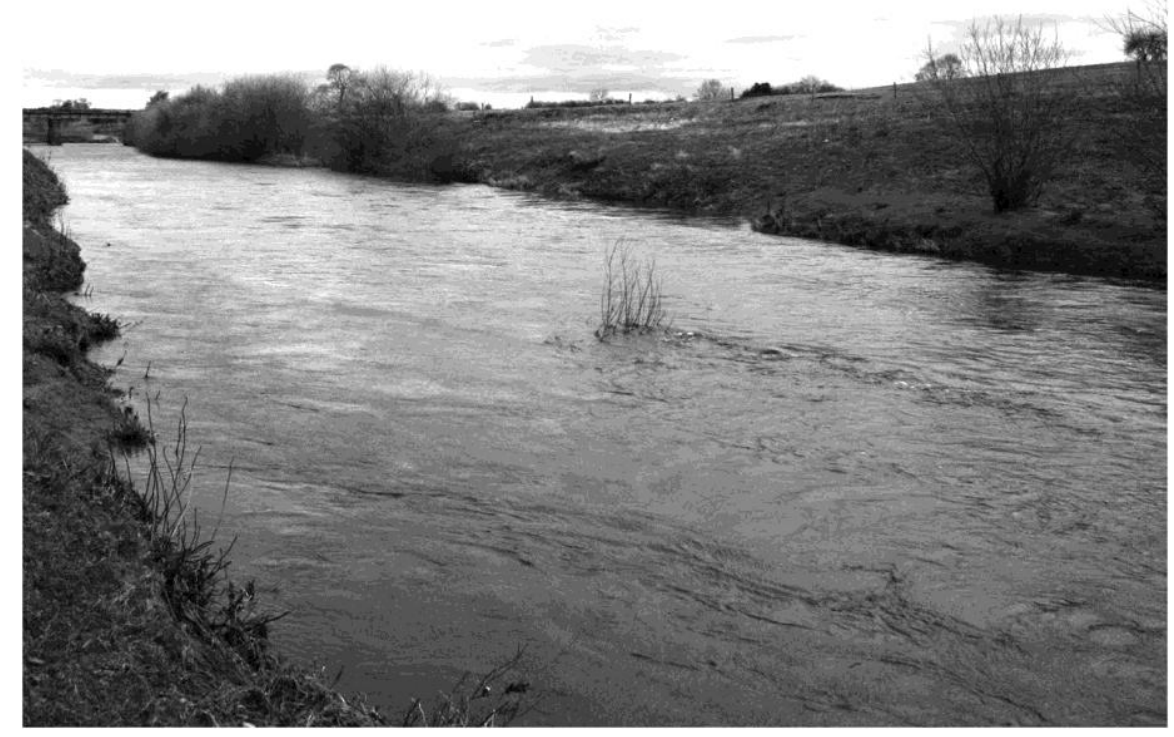


Figure 2. Looking for larvae in Cod Beck on 26 June 2008.

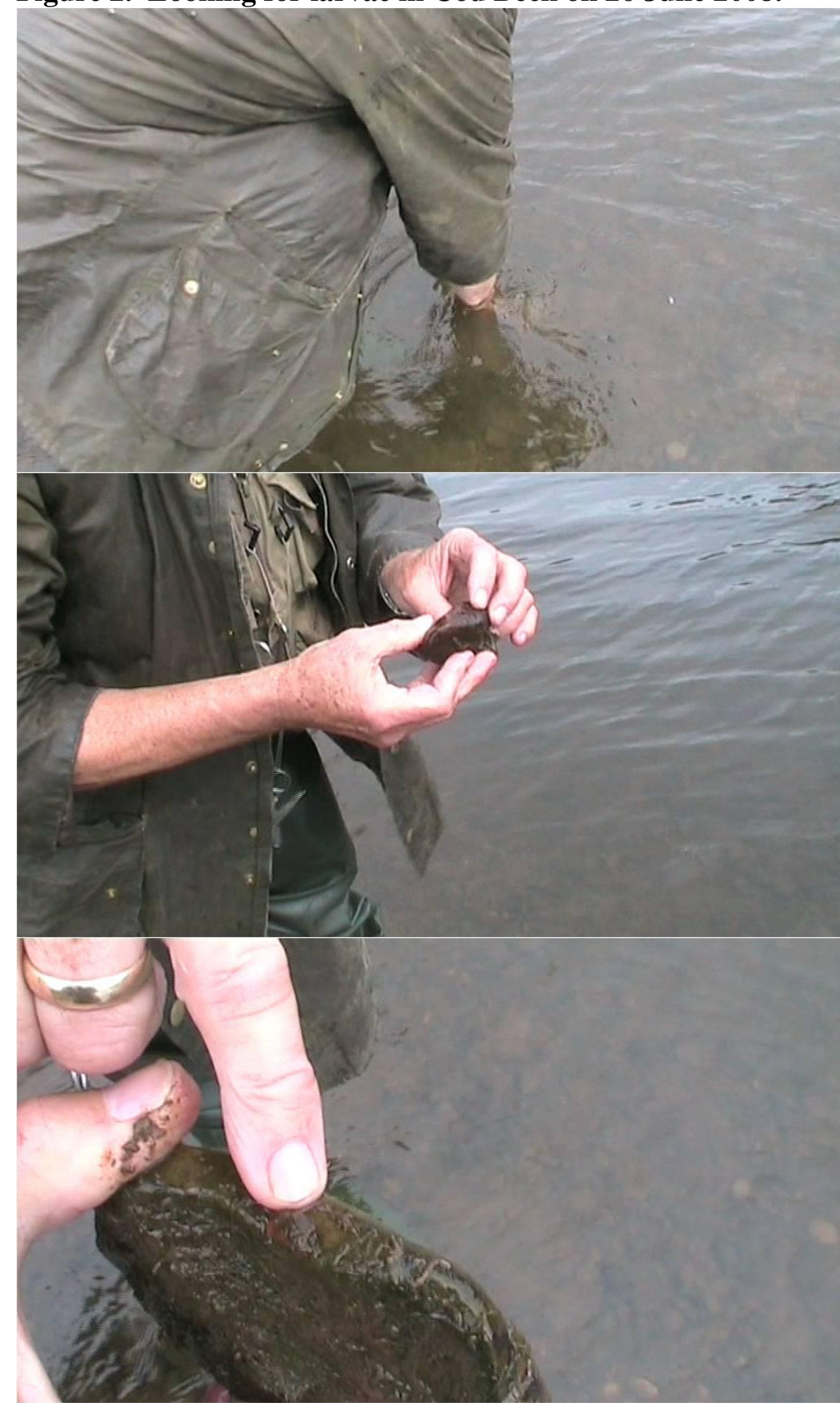

In the final photograph, the angler points to a small nymph crawling across a rock, a nymph of the same species represented by the artificial fly that he is using at the time.

\section{Notes}

\footnotetext{
${ }^{1}$ Sport England, Active People Survey (2006).

${ }^{2}$ Arkenford, Watersports and Leisure Participation Survey 2006 (Guildford, Arkenford 2006). Rod licences are legally required for anyone over the age of 12 fishing for salmon, trout, freshwater fish or eels in England and Wales, and are sold and regulated by the Environment
} 
Agency - see 'Angling is booming!' at http://www.environment-

agency.gov.uk/homeandleisure/recreation/fishing/108393.aspx accessed 2 July 2009.

${ }^{3}$ For example: Mike Michael, 'These boots are made for walking...: mundane technology, the body and human-environment relations', Body \& Society 6, 3-4 (2000), pp.107-126; Tim Ingold, 'Culture on the ground: the world perceived through the feet', Journal of Material Culture 9, 3 (2004), pp.315-340; Gordon Waitt, Nicholas Gill and Lesley Head, 'Walking practice and suburban nature-talk', Social \& Cultural Geography 10, 1 (2009), pp.41-60; John Wylie, 'A single day's walking: narrating self and landscape on the South West Coast Path', Transactions of the Institute of British Geographers 30, 2 (2005), pp.234-247.

${ }^{4}$ Echoing the account of how suburban lawns shape (and require) 'turfgrass subjects' in Paul Robbinsm, Lawn People: How Grasses, Weeds, and Chemicals Make Us Who We Are (Temple University Press, 2007)

${ }^{5}$ Similarly, this paper has little room to deal with angling explicitly as an encounter between anglers and fish, an issue we have addressed elsewhere.

6 Environment Agency, Fishing for the future (Bristol, Environment Agency, 2006), p.6;

Cecily Maller, Mardie Townsend, Anita Pryor, Peter Brown and Lawrence St Leger, 'Healthy nature healthy people: 'contact with nature' as an upstream health promotion intervention for populations', Health Promotion International 21, 1 (2005), pp.45-54; Natural England, A Manifesto for the Natural Environment (Natural England 2008) http://naturalengland.communisis.com/naturalenglandshop/docs/NE95.pdf , accessed 15 January 2009; Bill McKibben, The end of nature (London, Penguin, 1990).

${ }^{7}$ David Matless, 'Moral geographies of English landscape', Landscape Research 22, 2 (1997) pp.141-155; Peter Merriman, 'Respect the life of the countryside': the Country Code, government and the conduct of visitors to the countryside in post-war England and Wales', Transactions of the Institute of British Geographers 30, 3 (2005) pp.336-350; Gavin Parker, 'The Country Code and the ordering of countryside citizenship', Journal of Rural Studies 22 (2006) pp.1-16.

${ }^{8}$ Examples include anthropologists, sociologists and human geographers, such as: Ingold, 'Culture on the ground'; Tim Ingold, The perception of the environment (Abingdon, Routledge 2000); Tim Ingold, 'The temporality of the landscape', World Archaeology 25, 2, (1993) pp.152-174; Bruno Latour, Reassembling the social: an introduction to actor-networktheory (Oxford, Oxford University Press 2005). Bruno Latour, We have never been modern (Hemel Hempstead, Harvester Wheatsheaf 1993); Sarah Whatmore, Hybrid geographies (London, Sage, 2002); Steve Hinchliffe, Geographies of nature (London, Sage, 2007).

9 Phil Macnaghten, 'Embodying the environment in everyday life practices', The Sociological Review 51, 1 (2003), p.75.

${ }^{10}$ Macnaghten and Urry, Contested natures, p.15.

${ }^{11}$ Latour, Reassembling the social.

${ }^{12}$ Phil Macnaghten and John Urry, Contested Natures (London, Sage 1998). Michael S Carolan, 'I do therefore there is': enlivening socio-environmental theory', Environmental Politics 18, 1 (2009); John Urry, Consuming Places (London, Routledge 1995). Paul Cloke and Harvey C Perkins, 'Cracking the canyon with the awesome foursome': representations of adventure tourism in New Zealand. Environment and Planning D: Society and Space 16, (1998) pp.185-218.

${ }^{13}$ Mario F Teisl and Kelly O'Brien, 'Who cares and who acts? Outdoor recreationists exhibit different levels of environmental concern and behaviour', Environment and Behavior 35 (2003), 4, 506-522; Michael A Tarrant and Gary T Green, 'Outdoor recreation and the predictive validity of environmental attitudes', Leisures Sciences 21 (1999) 17-30.

${ }^{14}$ Latour, Reassembling the social; Michael, These boots. 
${ }_{16}^{15}$ Waitt et al., Walking practice, p.44.

${ }^{16}$ Tim Ingold and Terhi Kurttila, 'Perceiving the environment in Finnish Lapland', Body \& Society 6, 3-4 (2000), p.193.

${ }^{17}$ Ingold, Perception, p.316 and p.353.

${ }^{18}$ Sarah Whatmore, 'Materialist returns: practising cultural geography in and for a more-thanhuman world', Cultural Geographies 13 (2006), p.603.

${ }^{19}$ David Crouch, 'Places around us: embodied lay geographies in leisure and tourism', Leisure Studies 19 (2000), pp.63-76. Cloke and Perkins, 'Cracking the canyon'.

${ }^{20}$ Most club matches are fairly low-key but fun-based competitions with prizes (usually by volume of fish caught) generated by small entry fees paid by competitors. Match dates are organised locally by negotiation between angling clubs, to reduce clashes between match dates. By being a (paying) member of several clubs, a match angler can take part in a match nearly every weekend during the fishing season.

${ }^{21}$ Environment Agency, Public attitudes to angling (Bristol, Environment Agency 2005) (http://www.environment-agency.gov.uk/commondata/acrobat/geho0805bjpree 1153660.pdf ${ }^{22}$ Mintel, Sporting activities in the great outdoors - UK (2006).

${ }^{23}$ A. Whitney Sanford, 'Pinned on karma rock: Whitewater kayaking as religious experience', Journal Of The American Academy Of Religion 75 (2007), p.880.

${ }^{24}$ Ingold and Kurttila, 'Perceiving the environment'; Ingold, 'Perception'.

${ }^{25}$ Barbara Adam, Time and social theory (Cambridge, Polity Press, 1990), p.87.

${ }^{26}$ Ingold, Perception.

${ }^{27}$ Macnaghten and Urry, Contested natures; Urry, Consuming places; Ingold, Perception.

${ }^{28}$ Such as Terry Hartig and Henk Staats, 'Restorative environments', Journal of Environmental Psychology 23 (2003) pp.103-107.

${ }^{29}$ Ingold and Kurttila, 'Perceiving the environment', p. 189.

${ }^{30}$ Gordon Waitt and Lauren Cook, 'Leaving nothing but ripples on the water: performing ecotourism natures', Social \& Cultural Geography 8, 4 (2007), p.547.

${ }^{31}$ In contrast, Cloke and Perkins, 'Cracking the canyon', p. 212, note how advertisements for adventure tourism in New Zealand emphasise embodiment through physiological reactions (pulse rate etc.) to the experience, an expectation that is "reinforced by the actual experiences of tourism" in which tourists do not merely gaze but also perform. However, their own research cannot confirm that through tourists' experiences.

${ }^{32}$ Ingold, 'Culture on the ground', p.330.

${ }^{33}$ Ingold, 'Culture on the ground', p.332.

${ }^{34}$ Ingold, Perception.

${ }^{35}$ Michael, 'These boots', p.112.

${ }^{36}$ Michael, 'These boots', p.122.

${ }^{37}$ Ingold, Perception, p.353.

${ }^{38}$ This is despite Adrian Franklin, 'New-Darwinian leisures, the body and nature: hunting and angling in modernity', Body \& Society 7, 4 (2001), p.57-76.

${ }^{39}$ Samuel Snyder, 'New streams of religion: fly fishing as a lived, religion of nature', Journal Of The American Academy Of Religion 75 (2007), pp.909-10.

${ }^{40}$ Tim Dant, Material culture in the social world (Buckingham, Open University Press 1999); Sanford, 'Pinned on karma rock', p.882, italics in original.

${ }^{41}$ Sanford, 'Pinned on karma rock, p.881.

42 Arthur Ransome, Rod and line (Oxford, Oxford University Press 1980 [first published 1929]), p.32. Ransome was famously the author of the children's book, Swallows and Amazons, but also wrote a regular angling column for the Manchester Guardian in the 1920s, based on his own fishing experiences. 
${ }^{43}$ We could also add that practice involves physically changing environments, e.g. adding gravel, removing obstructions in the water flow and recontouring river banks with bulldozers, to literally remake places through three-dimensional alterations. There is little room here to address this, although Cloke and Perkins, 'Cracking the canyons', p.212, briefly note such activities are also undertaken by whitewater rafting operators in New Zealand.

${ }^{44}$ Crouch, 'Places around us', p.67.

${ }^{45}$ Carolan, 'I do', p.5.

${ }^{46}$ Sanford, 'Pinned on karma rock', p.883; Cloke and Perkins, 'Cracking the canyon', p.204.

${ }^{47}$ Sanford, 'Pinned on karma rock', p.886.

${ }^{48}$ There is again little room in this paper to address how far anglers are 'becoming fish', but we have addressed such questions elsewhere.

${ }^{49}$ We note also that this detailed environmental engagement is rarely seen by anglers and their non-angling family members as praiseworthy or even valued. Instead, when we visited anglers at home to interview them, their commitment to angling was often denigrated by others (and even themselves) as something to be laughed at rather than celebrated, which perhaps reflects how such specialised practices are characterised as 'other' to modern society.

${ }^{50}$ Macnaghten and Urry, Contested natures, p.200.

${ }^{51}$ Macnaghten and Urry, Contested natures, p.211.

${ }^{52}$ Macnaghten, 'Embodying the environment'; Bron Taylor, 'Surfing into spirituality and a new, aquatic nature religion', Journal Of The American Academy Of Religion 75 (2007), pp.923-951. 